\title{
Temperature-induced hormesis in plants
}

\author{
Evgenios Agathokleous $^{1,2} \cdot$ Mitsutoshi Kitao $^{1} \cdot$ Hisanori Harayama ${ }^{1} \cdot$ \\ Edward J. Calabrese ${ }^{3}$
}

Received: 27 July 2018/Accepted: 25 August 2018/Published online: 11 September 2018

(C) The Author(s) 2018

\begin{abstract}
Environmental change attracts particular attention by biologists concerned with the performance of biological systems under stress. To investigate these, doseresponse relationships should be clarified. It was previously assumed that the fundamental nature of biological doseresponses follows a linear model, either with no threshold or with a threshold below which no effects are expected to occur in biological endpoints. However, substantial literature, including widespread documentation in plants, has revealed that hormesis commonly occurs. Hormesis is highly generalized and can be utilized as a quantitative measure of biological plasticity. Conditioning induced by adaptive responses also occurs in the framework of hormesis and is of particular importance to environmental change biology with regards to evolutionary adaptations. This paper presents additional evidence for hormetic dose
\end{abstract}

Project funding: This research was supported by JSPS KAKENHI Grant Number JP17F17102, the US Air Force [AFOSR FA9550-13-10047] and ExxonMobil Foundation [S18200000000256].

The online version is available at http://www.springerlink.com

Corresponding editor: Yu Lei.

Evgenios Agathokleous

evgenios@ffpri.affrc.go.jp

1 Hokkaido Research Center, Forestry and Forest Products Research Institute (FFPRI), Forest Research and Management Organization, 7 Hitsujigaoka, Sapporo, Hokkaido 062-8516, Japan

2 Research Faculty of Agriculture, Hokkaido University, Kita 9 Nishi 9, Sapporo, Hokkaido 060-8589, Japan

3 Department of Environmental Health Sciences, Morrill I, N344, University of Massachusetts, Amherst, MA 01003, USA responses induced by temperature in plants. The current understanding on hormesis provides a perspective for next generation environmental change research. Hormesis should have a central role in environmental change biology of vegetation.

Keywords Adaptive response - Biological plasticity · Dose response $\cdot$ Hormesis $\cdot$ Stress biology

\section{Introduction}

Environmental change is the focus for biologists concerned with the functioning of biological systems under stress. How biological systems respond to environmental stressors, what capacity biological systems have to adapt, and what are "safe" levels of environmental change "stress" factors to not only avoid adverse effects but also to enhance productivity, are some of the many questions puzzling scientists dealing with environmental change biology, policy and decision makers, and governments.

At the center of these biological questions is the doseresponse relationship, a pillar of toxicology and fundamental in biology which guides the assessment of environmental tolerances. Throughout the 20th century, it was assumed that the fundamental nature of dose-response relationships (Fig. 1) was either linear or a threshold below which no effects were expected (Calabrese 2016a, 2017a, b). Linear non-threshold (LNT) and threshold models have been widely applied and adopted by worldwide regulatory agencies for human cancer and noncancer endpoints, (e.g., endocrine disruptor agents), but also for the effects of air pollutants on vegetation as in the case of ground-level ozone (Fuhrer et al. 1997; USEPA 
Fig. 1 Hypothetical linear nonthreshold, LNT (a), threshold (b) and hormesis (c, d) doseresponse models. Hormesis provides quantitative estimates on the limits of biological plasticity, and appears as inverse $U$-shape (c) or $U$-shape (d) dose-response curve, depending on the endpoint. For example, inverse $U$-shape curve would appear for net

photosynthetic rate and biomass whereas a $U$-shape curve would appear for hydrogen peroxide and non-photochemical quenching. Notes:

Toxicological threshold in the LNT model indicates a threshold of zero dose, i.e. practically no traditional threshold. NOEL and ZEP indicate no observed effect level and zero equivalent point (i.e., toxicological thresholds) for the threshold and hormesis models. MAX indicates the maximum stimulatory response in the hormesis model
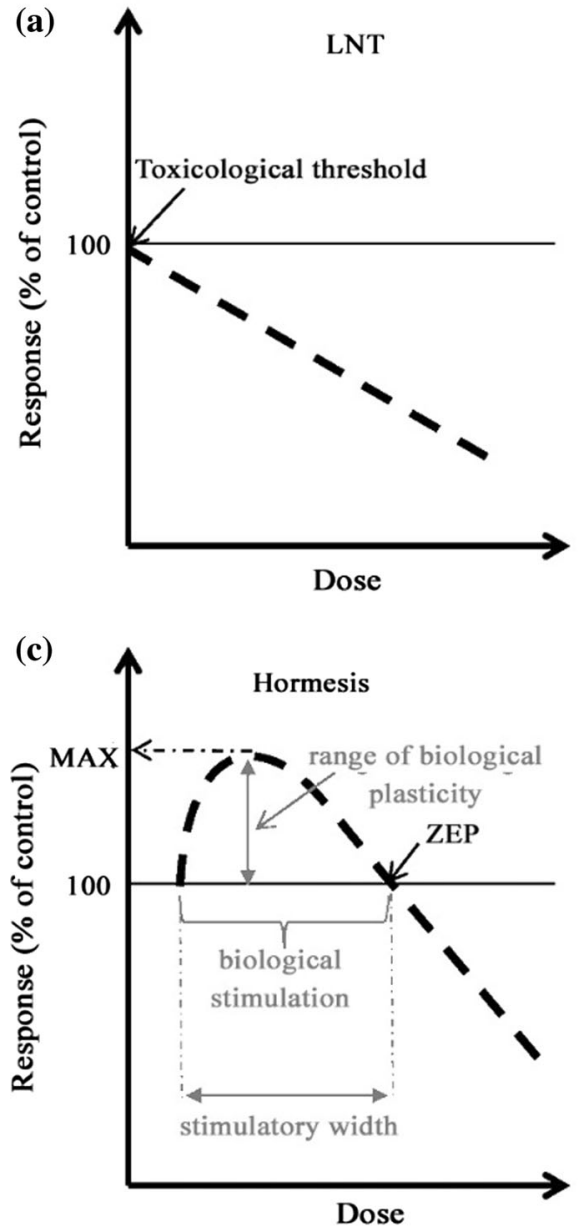
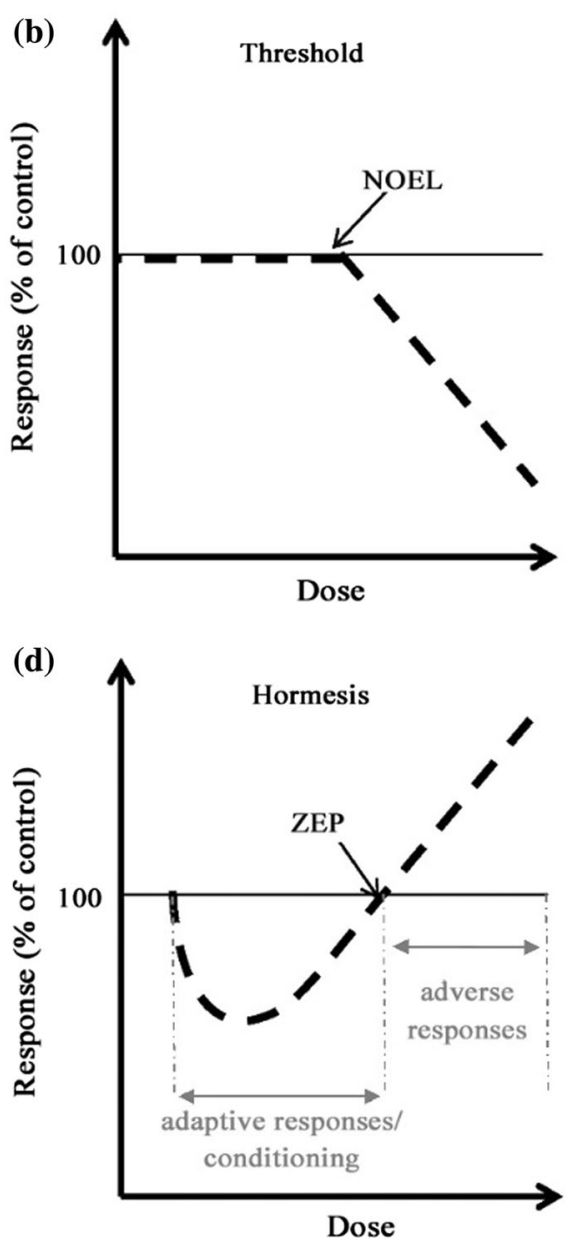

1998, 2013; WHO 2000a, 2006; Enstrom 2005, 2017; Mills et al. 2007; Zoeller et al. 2015; Bogen 2016, 2017).

The problem with the adoption and use of these two dose-response models that regulatory agencies employ is that they are accompanied by thousands of exceptions (Calabrese 2016a, 2017a, b). The vast majority of these reflect biphasic dose responses commonly referred to as hormesis (Calabrese and Blain 2011; Calabrese 2017c; Calabrese and Mattson 2017; Agathokleous 2018; Agathokleous et al. 2018a, b; Kim et al. 2018).

In light of recent significant progress in the field of dose response, this paper examines the question of whether hormesis should have a central role in vegetation environmental change biology or be ignored or even marginalized. In the framework of this examination, plant response to air temperature is provided as a paradigm of the occurrence of hormesis in vegetation environmental change biology.

\section{The biological basis of the phenomenon of hormesis}

Hormesis (Fig. 1) is a dose-response phenomenon where low doses induce stimulation and high doses induce inhibition (Stebbing 2003). The differentiation of the biological response between the low and high dose zones, as seen in the hormetic model, has generated considerable scientific curiosity about the biological mechanisms underpinning the response. Therefore, the biological mechanisms have been widely studied, and there is now available a large record documenting such processes (Calabrese 2013, 2016b, c; Calabrese and Mattson 2017).

These findings suggest that the concept of hormesis can be utilized as a quantitative measure of biological plasticity, i.e., the organism capacity to re-arrange biological functions via the activation of adaptive responses under the influence of stress (Calabrese and Blain 2011; Calabrese and Mattson 2017; Agathokleous 2018). By studying hormetic dose responses, the quantitative limits of biological plasticity can be clarified (Fig. 1). Meta-assessment of $\approx 9000$ dose responses revealed that the maximum 
stimulatory response is commonly less than two-fold the control response, and that the stimulatory width is within $\approx 10-20$-fold of the estimated toxicological threshold (Calabrese and Blain 2011). These features of hormesis indicate its links to evolutionary processes and may provide an important perspective in environmental change biology.

When adaptive responses are activated by low-level stimuli they often elicit therapeutic properties, especially with regards to aging-related homeostasis disruptions and malfunctions (Calabrese et al. 2018; Son et al. 2008). The therapeutic properties of adaptive responses are now well recognized in medicine and find application in combating human diseases. Adaptive responses within a hormetic framework would have important implications to vegetation environmental change biology and could provide a further perspective for biosphere sustainability (Calabrese and Mattson 2017).

Conditioning is also a manifestation of hormesis (Calabrese 2016b, c). Pre- and post-conditioning are the phenomena, where a prior experience of low-level stress protects against a subsequent high-level stress, and where a low-level stress following closely after high-level stress may alleviate much of the induced injury (Calabrese $2016 b$, c). Pre- and post-conditioning occur in the framework of hormesis and are of particular importance to environmental change biology in terms of significant evolutionary adaptations. Conditioning that may naturally occur in the environment, i.e., via activation of adaptive responses by low-level stress, may mediate biological responses to environmental change. Current understandings about pre- and post-conditioning open new doors to the next generation of environmental change research.

\section{Hormesis in plants}

While indications for hormesis existed from the late 1880s, including effects on plants (Calabrese and Baldwin 2000), the concept remained marginalized until recently. Numerous studies now exist showing that hundreds of chemicals and environmental pollutants and environmental change factors such as radiation, nitrogen deposition, ground-level ozone, and sulfur dioxide, induce hormesis in plants at various organizational (i.e., cell, organ, organism, and community) levels (Cedergreen et al. 2007; Son et al. 2008; Costantini et al. 2010; Calabrese and Blain 2011; Belz and Piepho 2013, 2015; Gressel and Dodds 2013; Poschenrieder et al. 2013; Hashmi et al. 2014; Agathokleous 2017, 2018; Belz and Duke 2017; Pagano 2017; Agathokleous et al. 2018a, b, c; Kim et al. 2018; Murakami 2018).
Hormetic effects of chemicals and radiation on plants have been extensively documented since the "rediscovery" of hormesis in the late 1970s. However, this was not the case with environmental factors on plants. Although there was evidence for hormesis induced by environmental factors (including pollutants) in plants, such as for ozone, nitrogen deposition, and sulfur dioxide via the documentation of low-dose stimulation and high-dose inhibition (Bennett et al. 1974; Roberts 1984; Darrall 1989), the possibility of hormesis was not considered for a long time. The concept of hormesis was proposed in a book chapter as a potential response of plants to ozone (Jaeger and Krupa 2009). Furthermore, in a book chapter of the World Health Organization (WHO) on the effects of nitrogen deposition, it was suggested that nitrogen deposition stimulates growth at lower levels and inhibits growth at higher levels, i.e., implying the occurrence of the phenomenon of hormesis (WHO 2000b). Recent literature reviews suggest that, when the experimental design permits testing the possibility of hormesis, environmental change factors, including ozone and nitrogen deposition, often induce hormesis in vegetation even at community or ecosystem levels (Agathokleous 2018; Agathokleous et al. 2018a, b).

Hormetic dose responses occur frequently, being independent of biological model (organism), endpoint, stressor and mechanism, suggesting widespread generality (Calabrese and Blain 2011; Calabrese 2013, 2014; Calabrese and Mattson 2017; Agathokleous 2018; Agathokleous et al. 2018a, b, c). The substantial evidence for non-linear biological/physiological processes produced endogenously or after a homeostatic disruption by exogenous agents, challenges the long-held belief that the fundamental nature of biological responses is some combination of threshold and non-threshold linear processes.

\section{Plant response to temperature: an interesting example of hormesis}

Temperature holds a crucial role in global change biology as the average global surface temperature appears to have increased over the last decades (Wen et al. 2011; Shi et al. 2018). Therefore, it is important to understand how plants respond to temperature within a dose-response continuum.

Air temperature is a critical factor for organismal health, and biota have evolved complex biological mechanisms to regulate body temperature, including organisms which cannot move but still have evolved mechanisms for regulating internal temperature (Wigge 2013; Szymańska et al. 2017; Körner and Hiltbrunner 2018). A large amount of literature deals with the effects of air temperature on plants. A review study has suggested that a variety of tree species shows a positive response to elevated temperature (Saxe 
et al. 2002). A recent meta-analysis also suggests that a temperature increase of $0.3-10{ }^{\circ} \mathrm{C}$ enhanced growth, productivity, and health overall of woody plants (Yuan et al. 2018).

In their Tansley review, Saxe et al. (2002), in the supplement to their findings for positive tree response to elevated temperature, have questioned "but how close are we to the optima?" This question would be answered by studying dose-response relationships. However, there is a lack of sufficiently high number of exposure levels in dose-response experiments and narrow spacing of exposure levels, especially when the stressor agent is an environmental factor such as temperature, ozone, and carbon dioxide due to technical difficulties compared to studies with chemical agents.

Here, we examine the literature and provide for the first time collective evidence for temperature-induced hormesis in plants (Fig. 2).

As early as the 1960s, hormesis was revealed for the foliage yield of warm temperate, cool temperate and winter annual species in response to soil temperature; the maximum stimulatory response was in the temperature range of 12.5-27.5 ${ }^{\circ} \mathrm{C}$ (Davidson 1969). In the 1970s, a report was published after an extensive experimentation on the effects of ozone and sulfur dioxide on oat (Avena sativa L.) varieties (Heck and Dunning 1976). This research was sponsored by the Agricultural Research Service (ARS), Environmental Protection Agency (EPA), and the North Carolina Agricultural Experiment Station of the U.S, and was prepared for the Office of Research and Development of the EPA. In this study, the response of oat plants to four temperature levels in the rage $18-30{ }^{\circ} \mathrm{C}$ was studied under different sulfur dioxide levels and relative humidities. These results suggested the occurrence of hormesis in top and root dry weight of oat plants exposed four times, three hours per time, in each experiment (Heck and Dunning 1976). This was seen in controlled environments with modified temperatures only (Fig. 2a), under different sulfur dioxide levels (Fig. 2b), and under different sulfur dioxide exposures for two different relative humidity levels (Fig. 2c, d). The results also suggested that temperatureinduced hormesis is modified/offset by other environmental conditions such as relative humidity and sulfur dioxide. Hormetic dose response was also found in the number of pods of snap bean (Phaseolus vulgaris L.) plants exposed to different levels of air temperature at 82 days after seeding (Fig. 2e) (Agathokleous et al. 2017).

Indications for hormesis were also observed in several biological/physiological endpoints of different plant species. One example was the response of gas exchange to growth temperatures investigated in the temperate evergreen tree species Quercus myrsinaefolia Blume (Hikosaka et al. 1999). Hormetic-like dose-response relationships were observed for gross photosynthetic rate (net photosynthetic rate + dark respiration) and potential rate of ribulose bisphosphate (RuBP) carboxylation (Fig. 2f). Hormetic-like dose-response relationships of net photosynthesis to leaf or mean monthly temperature has been also revealed in numerous species from a variety of families (Ishikawa et al. 2007; Vårhammar et al. 2015; Slot and Winter 2016, 2017; Slot et al. 2016; Benomar et al. 2018; Zhang et al. 2018). Another example is a hormetic-like response of dimethylallyl diphosphate (DMADP) pool, precursor of leaf-emitted isoprene, to leaf temperatures observed in hybrid aspen (Populus tremula $\times$ P. tremuloides) (Rasulov et al. 2011) (Fig. 2g). Likewise, a hormetic-like response in leaf anthocyanin content of Betula hybrid 'Royal Frost' (Betula populifolia 'Whitespire' $\times B$. populifolia 'Crimson Frost') seedlings to temperature was found; maximum stimulatory response was observed at $20{ }^{\circ} \mathrm{C}$ (Yang et al. 2017). Interestingly, a $U$-shaped curve of litter decomposition in response to climate (cooler to warmer) was also hypothesized in a recent study on early stage litter decomposition across biomes (Djukic et al. 2018), which remains to be validated by narrow-spaced dose-response experiments.

Slot and Winter (2016) suggested that the temperature where the maximum response (Fig. 1) occurs reflects the optimum temperature at which optimum photosynthesis occurs in the short-term temperature response. They also proposed that the $U$-shaped curve moves to the right of the $\mathrm{X}$-axis and up the $\mathrm{y}$-axis with higher photosynthesis response when plants are grown under warmer or hot conditions with a constructive adjustment (both optimum temperature and optimum photosynthesis increase). Furthermore, they proposed that the $U$-shaped curve moves to the right of the $\mathrm{x}$-axis but down the $\mathrm{y}$-axis with a lower photosynthesis response when plants are grown under warmer or hot conditions with a detractive adjustment (optimum photosynthesis decreases with increasing temperature) (Slot and Winter 2016). This is an interesting proposal which falls within the concept of hormesis as it has been shown for various animal models, i.e., conditioning (Calabrese 2016c).

Using quantitative estimates of dose-response relationships, important information can be obtained as to the biological plasticity of plants. As an example, we use a dose-response relationship for the maximum potential electron transport rate $\left(J_{\max }\right)$ of white spruce (Picea glauca (Moench) Voss) to needle temperature (Benomar et al. 2018). Dose-response relationships were obtained for plants from either a southern seed source or a northern seed source (Fig. 2h). These relationships suggest that plants from a northern seed source show a maximum response of $J_{\max }$ at $5{ }^{\circ} \mathrm{C}$ higher than plants from a southern seed source. In addition, temperature limits within which $J_{\max }$ is 
(a)

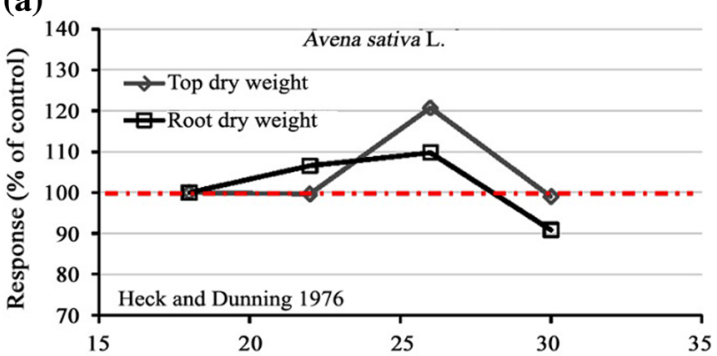

(b)

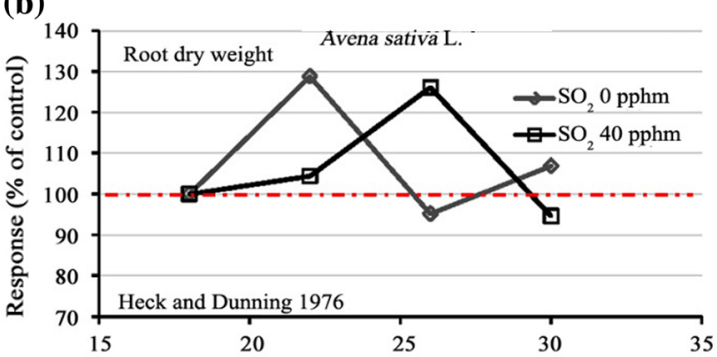

(c)

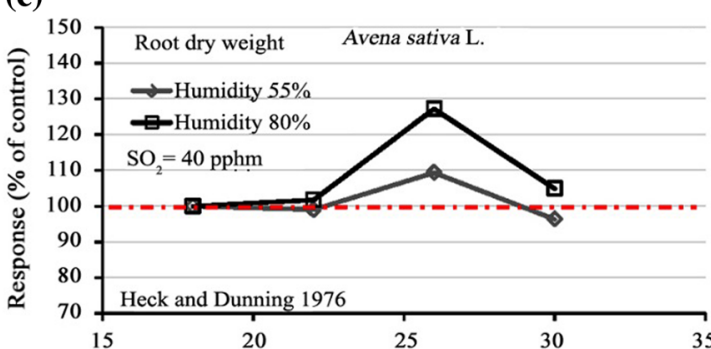

(d)

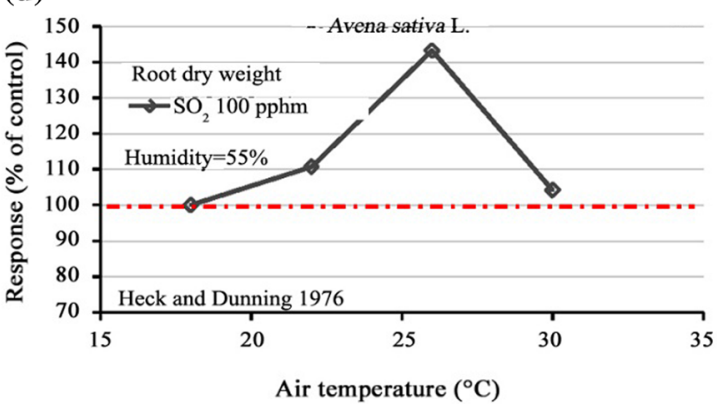

Fig. 2 Preliminary examples of hormetic-like responses of plants to temperature. Dose and response data presented only in figures in the reviewed articles were estimated using image analysis software (Adobe Photoshop CS4 Extended v.11, Adobe Systems Incorporated, CA, USA). $J_{\max }$ is the maximum potential electron transport rate. Notes: In the experiment of Rasulov et al. (2011), control was considered the leaf temperature closer to the day temperature under

up to $10 \%$ lower than the maximum response of $J_{\max }$ may provide a range of temperatures within which an approximate maximum response of $J_{\max }$ occurs and a plasticity range of $J_{\max }$ values (Fig. $2 \mathrm{~h}$ ).

The discussion raises two ecologically important questions, the first one being whether a temperature-induced hormetic dose-response curve corresponds to the curve of (e)

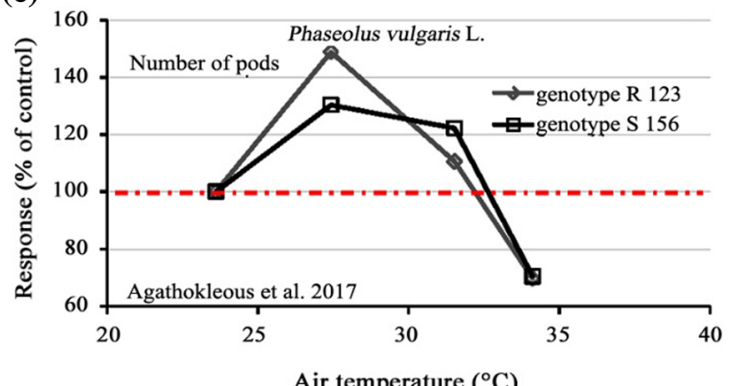

(f)

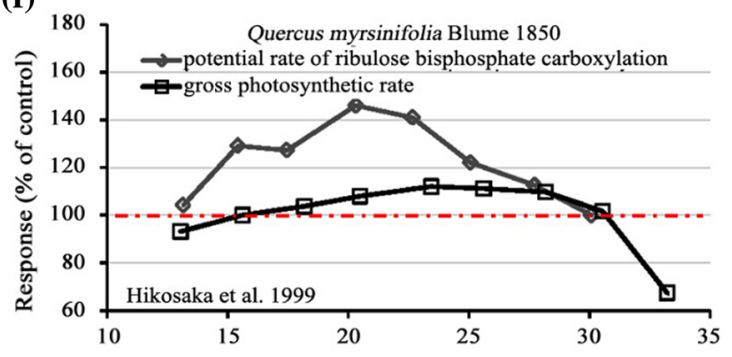

(g)

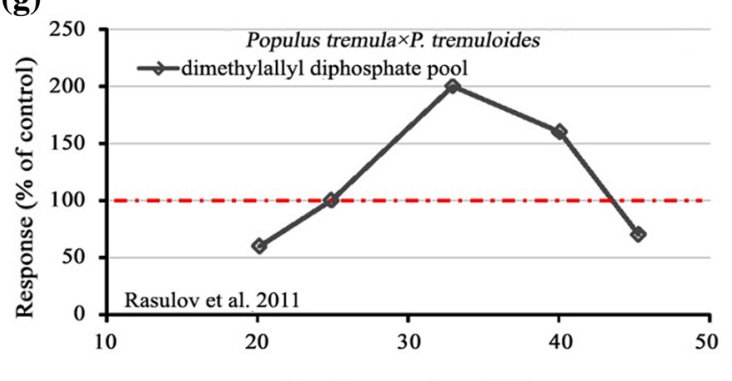

(h)

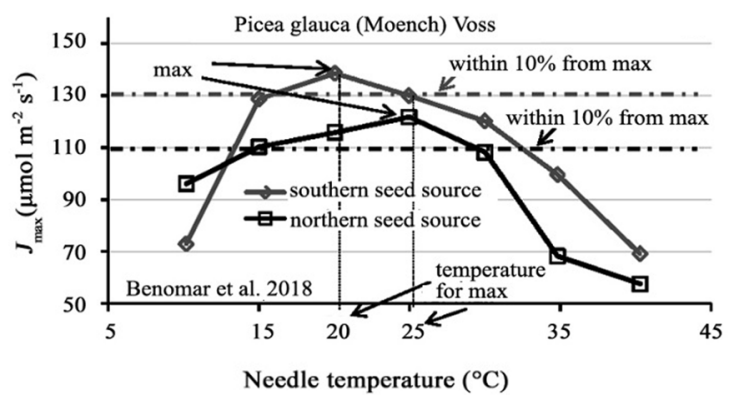

which plants were grown $\left(26^{\circ} \mathrm{C}\right)$. The values in Hikosaka et al. (1999) were averaged per target temperature, and the response data were corrected based on the group of control values to avoid overestimation. The control was $30{ }^{\circ} \mathrm{C}$ for the potential rate of ribulose bisphosphate (RuBP) carboxylation and $15^{\circ} \mathrm{C}$ for the gross photosynthetic rate

Shelford's law of tolerance (Shelford 1931), and the second whether the hormetic zone corresponds to the optimal temperature range for plants. Indeed, the examples presented are in agreement with Shelford's curve, where an organism has an optimum and a minimum and maximum level of a single stressor or mixture of stressors which determine success (Shelford 1931). Similarly, while the 
optimal temperature range for plants varies with a variety of factors, with the stage in ontogeny being a major driver, the hormetic zone is expected to correspond to the optimal temperature range under certain conditions, i.e., at certain stages of ontogeny (Abrami 1972; Hatfield and Prueger 2015).

\section{Conclusion}

We summarize, for the first time, examples of hormetic dose responses induced by temperature in plants. Temperature-induced hormesis is in agreement with extensive evidence from studies with insects, animals, and fungi (Rattan 2005; Sørensen et al. 2008; Vaiserman 2010). These research programs suggest that hormesis is independent of biological models and re-affirm the notion that hormesis is a fundamental biological phenomenon which occurs independently of stressor types, and not only upon agents which were previously considered "toxic".

Recent developments in plant science, along with the examples presented in this Review, underline the possibility that hormesis should be implemented in the design of vegetation-environmental change dose-response studies. These developments are important in ecotoxicological studies for understanding the mechanisms and processes whereby chemicals exert their effects on ecosystems.

The latter suggestion does not imply that a hormetic dose-response model is more appropriate than the threshold or linear non-threshold model (LNT). Which model will be more appropriate will be decided upon the doseresponse relationship; however, failure to incorporate the possibility of hormesis will result in failure to detect hormesis and eventually to misleading information for decision, policy, and regulation making.

Hormesis should have a central role in environmental vegetation change biology. The concept of environmental hormesis provides an important perspective for advancing the current scientific base of environmental change biology, ecology, and evolutionary biology research agendas.

Funding EA is an International Research Fellow (ID No: P17102) of the Japan Society for the Promotion of Science (JSPS).

Open Access This article is distributed under the terms of the Creative Commons Attribution 4.0 International License (http://crea tivecommons.org/licenses/by/4.0/), which permits unrestricted use, distribution, and reproduction in any medium, provided you give appropriate credit to the original author(s) and the source, provide a link to the Creative Commons license, and indicate if changes were made.

\section{References}

Abrami G (1972) Optimum mean temperature for a plant growth calculated by a new method of summation. Ecology 53:893-900

Agathokleous E (2017) Perspectives for elucidating the ethylenediurea (EDU) mode of action for protection against $\mathrm{O}_{3}$ phytotoxicity. Ecotoxicol Environ Saf 142:530-537

Agathokleous E (2018) Environmental hormesis, a fundamental nonmonotonic biological phenomenon with implications in ecotoxicology and environmental safety. Ecotoxicol Environ Saf 148:1042-1053

Agathokleous E, Saitanis CJ, Burkey KO, Ntatsi G, Vougeleka V, Mashaheet AM, Pallides A (2017) Application and further characterization of the snap bean S156/R123 ozone biomonitoring system in relation to ambient air temperature. Sci Total Environ 580:1046-1055

Agathokleous E, Kitao M, Calabrese EJ (2018a) The rare earth element (REE) lanthanum (La) induces hormesis in plants. Environ Pollut 238:1044-1047

Agathokleous E, Kitao M, Calabrese EJ (2018b) Emission of volatile organic compounds from plants shows a biphasic pattern within an hormetic context. Environ Pollut 239:318-321

Agathokleous E, Kitao M, Calabrese EJ (2018c) Biphasic effect of abscisic acid on plants: a hormetic viewpoint. Botany. https:// doi.org/10.1139/cjb-2018-0076

Belz RG, Duke SO (2017) Herbicide-mediated hormesis. In: Duke SO, Kudsk P, Solomon K (eds) Pesticide dose: effects on the environment and target and non-target organisms. American Chemical Society, Washington, pp 135-148

Belz RG, Piepho HP (2013) Variability of hormetic dose responses of the antiauxin PCIB on Lactuca sativa in a plant bioassay. Weed Res 53:418-428

Belz RG, Piepho HP (2015) Statistical modeling of the hormetic dose zone and the toxic potency completes the quantitative description of hormetic dose responses. Environ Toxicol Chem 34:1169-1177

Bennett JP, Resh HM, Runeckles VC (1974) Apparent stimulations of plant growth by air pollutants. Can J Bot 52:35-41

Benomar L, Lamhamedi MS, Pepin S, Rainville A, Lambert MC, Margolis HA, Bousquet J, Beaulieu J (2018) Thermal acclimation of photosynthesis and respiration of southern and northern white spruce seed sources tested along a regional climatic gradient indicates limited potential to cope with temperature warming. Ann Bot Lond 121:443-457

Bogen KT (2016) Linear-no-threshold default assumptions for noncancer and nongenotoxic cancer risks: a mathematical and biological critique. Risk Anal 36:589-604

Bogen KT (2017) Linear-no-threshold default assumptions are unwarranted for cytotoxic endpoints independently triggered by ultrasensitive molecular switches. Risk Anal 37:1808-1816

Calabrese EJ (2013) Biphasic dose responses in biology, toxicology and medicine: accounting for their generalizability and quantitative features. Environ Pollut 182:452-460

Calabrese EJ (2014) Hormesis: a fundamental concept in biology. Microb Cell 1:145-149

Calabrese EJ (2016a) LNTgate: how scientific misconduct by the U.S. NAS led to governments adopting LNT for cancer risk assessment. Environ Res 148:535-546

Calabrese EJ (2016b) Preconditioning is hormesis part I: documentation, dose-response features and mechanistic foundations. Pharmacol Res 110:242-264

Calabrese EJ (2016c) Preconditioning is hormesis part II: how the conditioning dose mediates protection: dose optimization within temporal and mechanistic frameworks. Pharmacol Res 110:265-275 
Calabrese EJ (2017a) LNTgate: the ideological history of cancer risk assessment. Toxicol Res Appl 1:239784731769499

Calabrese EJ (2017b) Obituary notice: LNT dead at 89 years, a life in the spotlight. Environ Res 155:276-278

Calabrese EJ (2017c) Hormesis commonly observed in the assessment of aneuploidy in yeast. Environ Pollut 225:713-728

Calabrese EJ, Baldwin LA (2000) Chemical hormesis: its historical foundations as a biological hypothesis. Hum Exp Toxicol 19:2-31

Calabrese EJ, Blain RB (2011) The hormesis database: the occurrence of hormetic dose responses in the toxicological literature. Regul Toxicol Pharmacol 61:73-81

Calabrese EJ, Mattson MP (2017) How does hormesis impact biology, toxicology, and medicine? Aging Mech Dis 3:13

Calabrese V, Santoro A, Monti D, Crupi R, Di Paola R, Latteri S, Cuzzocrea S, Zappia M, Giordano J, Calabrese EJ, Franceschi C (2018) Aging and Parkinson's disease: inflammaging, neuroinflammation and biological remodeling as key factors in pathogenesis. Free Radical Biol Med 115:80-91

Cedergreen N, Streibig JC, Kudsk P, Mathiassen SK, Duke SO (2007) The occurrence of hormesis in plants and algae. Dose Response 5:150-162

Costantini D, Metcalfe NB, Monaghan P (2010) Ecological processes in a hormetic framework. Ecol Lett 13:1435-1447

Darrall NM (1989) The effect of air pollutants on physiological processes in plants. Plant Cell Environ 12:1-30

Davidson RL (1969) Effect of root/leaf temperature differentials on root/shoot ratios in some pasture grasses and clover. Ann Bot 33:561-569

Djukic I, Kepfer-Rojas S, Schmidt IK et al (2018) Early stage litter decomposition across biomes. Sci Total Environ 628-629:1369-1394

Enstrom JE (2005) Fine particulate air pollution and total mortality among elderly Californians, 1973-2002. Inhal Toxicol $17: 803-816$

Enstrom JE (2017) Fine particulate matter and total mortality in cancer prevention study cohort reanalysis. Dose Response 15:1559325817693345

Fuhrer J, Skärby L, Ashmore MRR (1997) Critical levels for ozone effects on vegetation in Europe. Environ Pollut 97:91-106

Gressel J, Dodds J (2013) Commentary: hormesis can be used in enhancing plant productivity and health; but not as previously envisaged. Plant Sci 213:123-127

Hashmi MZ, Naveedullah Shen H, Zhu S, Yu C, Shen C (2014) Growth, bioluminescence and shoal behavior hormetic responses to inorganic and/or organic chemicals: a review. Environ Int 64:28-39

Hatfield JL, Prueger JH (2015) Temperature extremes: effect on plant growth and development. Weather Clim Extrem 10:4-10

Heck WW, Dunning JA (1976) Effects of sulfur dioxide and/or ozone on two oat varieties. Corvallis Environmental Research Laboratory, Corvallis

Hikosaka K, Murakami A, Hirose T (1999) Balancing carboxylation and regeneration of ribulose-1,5-bisphosphate in leaf photosynthesis: temperature acclimation of an evergreen tree, Quercus myrsinaefolia. Plant Cell Environ 22:841-849

Ishikawa K, Onoda Y, Hikosaka K (2007) Intraspecific variation in temperature dependence of gas exchange characteristics among Plantago asiatica ecotypes from different temperature regimes. New Phytol 176:356-364

Jaeger HJ, Krupa SV (2009) Hormesis-its relevance in phytotoxicology. In: Legge AH (ed) Air quality and ecological impacts: relating sources to effects. Elsevier, Hungary, pp 137-152

Kim S-A, Lee Y-M, Choi J-Y, Jacobs DR, Lee D-H (2018) Evolutionarily adapted hormesis-inducing stressors can be a practical solution to mitigate harmful effects of chronic exposure to low dose chemical mixtures. Environ Pollut 233:725-734

Körner C, Hiltbrunner E (2018) The 90 ways to describe plant temperature. Perspect Plant Ecol 30:16-21

Mills G, Buse A, Gimeno B, Bermejo V, Holland M, Emberson LD, Pleijel H (2007) A synthesis of AOT40-based response functions and critical levels of ozone for agricultural and horticultural crops. Atmos Environ 41:2630-2643

Murakami A (2018) Non-specific protein modifications may be novel mechanism underlying bioactive phytochemicals. J Clin Biochem Nutr 62:115-123

Pagano G (2017) Rare earth elements in human and environmental health: at the crossroads between toxicity and safety. Pan Stanford Publishing Pte. Ltd., Singapore, p 292

Poschenrieder C, Cabot C, Martos S, Gallego B, Barceló J (2013) Do toxic ions induce hormesis in plants? Plant Sci 212:15-25

Rasulov B, Hüve K, Laisk A, Niinemets Ü (2011) Induction of a longer term component of isoprene release in darkened aspen leaves: origin and regulation under different environmental conditions. Plant Physiol 156:816-831

Rattan S (2005) Hormetic modulation of aging and longevity by mild heat stress. Dose Response 3:533-546

Roberts TM (1984) Effects of air pollutants on agriculture and forestry. Atmos Environ 18:629-652

Saxe H, Cannell MGR, Johnsen Ø, Ryan MG, Vourlitis G (2002) Tree and forest functioning in response to global warming. New Phytol 149:369-399

Shelford VE (1931) Some concepts of bioecology. Ecology 12:455-467

Shi C, Jiang Z-H, Chen W-L, Li L (2018) Changes in temperature extremes over China under $1.5^{\circ} \mathrm{C}$ and $2{ }^{\circ} \mathrm{C}$ global warming targets. Adv Clim Change Res 9:120-129

Slot M, Winter K (2016) The effects of rising temperature on the ecophysiology of tropical forest trees. Tropical tree physiology. Springer, Cham, pp 385-412

Slot M, Winter K (2017) In situ temperature response of photosynthesis of 42 tree and liana species in the canopy of two Panamanian lowland tropical forests with contrasting rainfall regimes. New Phytol 214:1103-1117

Slot M, Garcia MN, Winter K (2016) Temperature response of $\mathrm{CO}_{2}$ exchange in three tropical tree species. Funct Plant Biol 43:468-478

Son TG, Camandola S, Mattson MP (2008) Hormetic dietary phytochemicals. Neuromol Med 10:236-246

Sørensen JG, Sarup P, Kristensen TN, Loeschcke V (2008) Temperature-induced hormesis in Drosophila. Mild Stress and Healthy Aging. Applying Hormesis in Aging Research and Interventions, Eds: Le Bourg E, Rattan S, pp 65-79, Springer

Stebbing ARD (2003) A mechanism for hormesis-a problem in the wrong discipline. Crit Rev Toxicol 33:463-467

Szymańska R, Ślesak I, Orzechowska A, Kruk J (2017) Physiological and biochemical responses to high light and temperature stress in plants. Environ Exp Bot 139:165-177

USEPA (1998) Guidelines for neurotoxicity risk assessment. Federal Register 63, pp 26926-26954

USEPA (2013) National ambient air quality standards for particulate matter; final rule. Federal Register 78

Vaiserman AM (2010) Hormesis, adaptive epigenetic reorganization, and implications for human health and longevity. Dose Response 8:16-21

Vårhammar $\mathrm{A}$, Wallin $\mathrm{G}$, McLean $\mathrm{CM}$, Dusenge ME, Medlyn BE, Hasper TB, Nsabimana D, Uddling J (2015) Photosynthetic temperature responses of tree species in Rwanda: evidence of pronounced negative effects of high temperature in montane rainforest climax species. New Phytol 206:1000-1012 
Wen X, Tang G, Wang S, Huang J (2011) Comparison of global mean temperature series. Adv Clim Change Res 2:187-192

Wigge PA (2013) Ambient temperature signalling in plants. Curr Opin Plant Biol 16:661-666

World Health Organization (WHO) (2000a) Air quality guidelines for Europe, 2nd edn. Reg. Publ. Eur. Ser., WHO Reg. Off. Eur., Copenhagen, p 288

World Health Organization (WHO) (2000b) Effects of nitrogen containing air pollutants: critical levels. In: Air quality guidelines. Regional Office for Europe, Copenhagen

World Health Organization (WHO) (2006) WHO Air quality guidelines for particulate matter, ozone, nitrogen dioxide and sulfur dioxide. Global update 2005, Summary of risk assessment. World Health Organization, Geneva, WHO/SDE/PHE/OEH/ $06.02 \mathrm{p}$
Yang L, Zhang D, Qiu S, Gong Z, Shen H (2017) Effects of environmental factors on seedling growth and anthocyanin content in Betula 'Royal Frost' leaves. J For Res 28:1147-1155

Yuan Y, Ge L, Yang H, Ren W (2018) A meta-analysis of experimental warming effects on woody plant growth and photosynthesis in forests. J For Res 29:727-733

Zhang X, Chen L, Wang J, Wang M, Yang S, Zhao C (2018) Photosynthetic acclimation to long-term high temperature and soil drought stress in two spruce species (Picea crassifolia and $P$. wilsonii) used for afforestation. J For Res 29:363-372

Zoeller RT, Vandenberg LN, Becher G, Bjerregaard P, Bornman R, Brandt I (2015) Assessing dose-response relationships for endocrine disrupting chemicals (EDCs): a focus on non-monotonicity. Environ Health 14:42 